\title{
Site-specific labeling of nucleotides for making RNA for high resolution NMR studies using an $E$. coli strain disabled in the oxidative pentose phosphate pathway
}

\author{
T. Kwaku Dayie - Chandar S. Thakur
}

Received: 14 December 2009/Accepted: 26 February 2010/Published online: 23 March 2010

(C) The Author(s) 2010. This article is published with open access at Springerlink.com

\begin{abstract}
Escherichia coli (E. coli) is a versatile organism for making nucleotides labeled with stable isotopes $\left({ }^{13} \mathrm{C},{ }^{15} \mathrm{~N}\right.$, and/or $\left.{ }^{2} \mathrm{H}\right)$ for structural and molecular dynamics characterizations. Growth of a mutant $E$. coli strain deficient in the pentose phosphate pathway enzyme glucose-6-phosphate dehydrogenase (K10-1516) on $2-{ }^{13} \mathrm{C}$-glycerol and ${ }^{15} \mathrm{~N}$-ammonium sulfate in Studier minimal medium enables labeling at sites useful for NMR spectroscopy. However, ${ }^{13} \mathrm{C}$-sodium formate combined with ${ }^{13} \mathrm{C}$-2-glycerol in the growth media adds labels to new positions. In the absence of labeled formate, both C5 and C6 positions of the pyrimidine rings are labeled with minimal multiplet splitting due to ${ }^{1} \mathrm{~J}_{\mathrm{C} 5 \mathrm{C} 6}$ scalar coupling. However, the $\mathrm{C} 2 / \mathrm{C} 8$ sites within purine rings and the $\mathrm{C} 1^{\prime} / \mathrm{C}^{\prime} / \mathrm{C}^{\prime}$ positions within the ribose rings have reduced labeling. Addition of ${ }^{13} \mathrm{C}$-labeled formate leads to increased labeling at the base $\mathrm{C} 2 / \mathrm{C} 8$ and the ribose $\mathrm{C} 1^{\prime} / \mathrm{C}^{\prime} / \mathrm{C}^{\prime}$ positions; these new specific labels result in twoto three-fold increase in the number of resolved resonances. This use of formate and ${ }^{15} \mathrm{~N}$-ammonium sulfate promises to extend further the utility of these alternate site specific labels to make labeled RNA for downstream biophysical applications such as structural, dynamics and functional studies of interesting biologically relevant RNAs.
\end{abstract}

Keywords Alternate-site specific labeling .

Formate enhanced isotope enrichment .

Ribose and nucleobase $\cdot$ RNA $\cdot$ Structure and dynamics

T. K. Dayie $(\varangle) \cdot$ C. S. Thakur

Department of Chemistry and Biochemistry, Center

for Biomolecular Structure and Organization, University

of Maryland, 1115 Biomolecular Sciences Bldg (\#296), College

Park, MD 20742-3360, USA

e-mail: dayie@umd.edu

$\begin{array}{ll}\text { Abbreviations } \\ \text { AMP } & \text { Adenosine } 5^{\prime} \text {-monophosphate } \\ \text { CMP } & \text { Cytidine } 5^{\prime} \text {-monophosphate } \\ \text { DHAP } & \text { Dihydroxyacetone phosphate } \\ \text { FBP } & \text { Fructose-6-bisphosphate } \\ \text { F6P } & \text { Fructose-6-phosphate } \\ \text { G6PDH } & \text { Glucose-6-phosphate dehydrogenase } \\ \text { GA3P } & \text { Glyceraldehyde-3-phosphate } \\ \text { Gly } & \text { Glycine } \\ \text { GMP } & \text { Guanosine 5'-monophosphate } \\ \text { noPPP } & \text { Non-oxidative pentose phosphate pathway } \\ \text { OAA } & \text { Oxaloacetate } \\ \text { oPPP } & \text { Oxidative pentose phosphate pathway } \\ \text { R5P } & \text { Ribose-5-phosphate } \\ \text { rNMPs } & \text { Ribonucleoside monophosphates } \\ \text { rNTPs } & \text { Ribonucleoside triphosphates } \\ \text { Ser } & \text { Serine } \\ \text { TIM } & \text { Triosephosphate isomerase } \\ \text { UMP } & \text { Uridine 5'-monophosphate }\end{array}$

Introduction

Nucleic acids and proteins can be labeled with stable isotopes for structural and dynamics studies (Dayie 2008) using E. coli as a common bacterial host (Ponchon and Dardel 2007; Ponchon et al. 2009), using enzymes from the pentose phosphate or de novo purine biosynthetic pathways (Gross et al. 1983; Parkin et al. 1984; Tolbert and Williamson 1996, 1997; Scott et al. 2000; Schultheisz et al. 2008), or using chemical synthesis (Milecki 2002).

Of these three methods, use of different $E$. coli bacteria grown on minimal media is attractive for a number of reasons. E. coli grown on chemically defined minimal 
media supplemented with ${ }^{15} \mathrm{~N}$-labeled nitrogen and ${ }^{13} \mathrm{C}$-labeled carbon sources (Batey et al. 1995; Hoffman and Holland 1995; Nikonowicz 2001; Latham et al. 2005; Dayie 2008) produces isotopically labeled total cellular RNA that can be enzymatically digested to nucleoside monophosphates (NMPs). The NMPs can be phosphorylated to the corresponding nucleoside triphosphates (NTPs) and these labeled NTPs become the building blocks for making labeled RNA using T7 RNA polymerase. Of the different $E$. coli strains that offer potential for uniform and alternate site specific ${ }^{13} \mathrm{C}$ isotopic labeling, the $E$. coli strain with a knockout of the $z w f$ gene is particularly attractive. Deleting the $z w f$ gene means this $E$. coli strain K10-1516 (hereafter referred to as K10) cannot encode the glucose-6-phosphate dehydrogenase (G6PDH) enzyme for use in the pentose phosphate pathway(PPP; Fraenkel 1968). Growth of this strain on $2-{ }^{13} \mathrm{C}$-glycerol without formate provides labeling mostly at the $\mathrm{C} 2{ }^{\prime}$ and $\mathrm{C}^{\prime}{ }^{\prime}$ ribose positions and at both $\mathrm{C} 5$ and $\mathrm{C} 6$ base positions of the cytidine monophosphate (CMP) with minimal multiplet splitting due to ${ }^{1} \mathrm{~J}_{\mathrm{C} 5 \mathrm{C} 6}$ scalar coupling (Johnson et al. 2006; Hoogstraten and Johnson 2008).

These previous labeling methods offered the advantage of enriching only a few specific sites such as $\mathrm{C} 8$ in purine (Pur, adenine or Ade and guanine or Gua) and ribose $\mathrm{C}^{\prime}$ and $\mathrm{C}^{\prime}$. However, there are at least two disadvantages with such schemes. First, many useful sites are only fractionally enriched. For example, the ribose $\mathrm{C}^{\prime}$ and $\mathrm{C}^{\prime}$ atoms and the purine $\mathrm{C} 2$ and $\mathrm{C} 8$ positions are labeled at a very low level when using $\mathrm{K} 10$. Yet the $\mathrm{C} 1^{\prime}$ carbon atoms have the most sugar chemical shift dispersion and $\mathrm{C}^{\prime}$ carbon atoms along with their attached protons can provide valuable $\gamma$-torsion angle information (Wijmenga and van Buuren 1998). In addition, the use of ${ }^{13} \mathrm{C}$-formate and ${ }^{12} \mathrm{C}$-glucose as the only carbon sources limits the incorporation of an isotopic label to the $\mathrm{C} 8$ position of adenine and guanine bases and precludes their use for other NMR studies. Second, it is more time and cost efficient if the same sample can be used for numerous applications such as the analyses of the function, structure and dynamics of RNAs. Limiting the labels to a few selected ribose and base atoms greatly lessens the general usefulness of the resulting nucleotides. Here we sought to extend the utility of these labels while preserving the advantage of isolating most of the spin systems of interest and boosting the isotopic enrichment level of the other useful NMR sites.

We reasoned that by combining ${ }^{13} \mathrm{C}$-glycerol with ${ }^{13} \mathrm{C}$ formate, all the protonated carbons of high interest for RNA NMR spectroscopy will be labeled in both purine and pyrimidine (Pyr, that is cytosine or Cyt, uracil or Ura, and thymine or Thy) bases. In addition, the isotopic enrichment at sites within the ribose ring will increase without introducing multiplet splitting at key atomic sites such as $\mathrm{C}^{\prime}{ }^{\prime}$ and $\mathrm{C}^{\prime}$. We can augment the level of isotopic enrichment at all the sites useful for proton-detected heteronuclear NMR experiments by adding ${ }^{13} \mathrm{C}$-formate to the ${ }^{13} \mathrm{C}$ glycerol growth media. Plus, the use of ${ }^{15}\left(\mathrm{NH}_{4}\right)_{2} \mathrm{SO}_{4}$ as the sole source of nitrogen leads to uniform and complete ${ }^{15} \mathrm{~N}$ labeling of all nitrogen positions in all nucleotides and it provides an alternative method for estimating the level of isotopic enrichment. This labeling method appears to be general and flexible, and affords a wide variety of purine and pyrimidine isotope labeling patterns useful for structural, functional and dynamics studies.

\section{Materials and methods}

\section{Bacterial strains}

The mutant strain K10-15-16 (CGSC \# 4858 Hfr fhuA22, $z w f-2$, relA1, $T 2 R, p f k-10)$ used in this work was obtained from the Yale Coli Genetic Stock Center.

\section{Isotopes}

All labeled compounds were bought from Cambridge Isotope Laboratory (Andover, MA) and Isotec-Sigma-Aldrich (Miamisburg, $\mathrm{OH}$ ) with the following isotopic enrichments: $\left[{ }^{13} \mathrm{C}\right]$ sodium formate $(99 \%),\left[2-{ }^{13} \mathrm{C}\right]$ glycerol $(99 \%)$ and $\left[{ }^{15} \mathrm{~N}\right]-\left(\mathrm{NH}_{4}\right)_{2} \mathrm{SO}_{4}(99 \%)$.

\section{Stock solutions}

The stock solutions required for bacterial growth were prepared using distilled and deionized heat sterilized water. The Studier medium (SPG) contained the following (Studier 2005): $25 \mathrm{mM} \cdot\left(\mathrm{NH}_{4}\right)_{2} \mathrm{SO}_{4}, 50 \mathrm{mM} \cdot \mathrm{KH}_{2} \mathrm{PO}_{4}$, $50 \mathrm{mM} \cdot \mathrm{Na}_{2} \mathrm{HPO}_{4}, 2 \mathrm{mM} \cdot \mathrm{MgSO}_{4}$ and trace metal solution; SPG was then supplemented with labeled glycerol or labeled formate and glycerol as needed.

\section{Media for bacterial growth}

Luria-Bertani (LB) and SPG minimal media were prepared as described (Sambrook and Russell 2001; Studier 2005). Each media was supplemented with the amount of the carbon source (sodium formate and glycerol) and nitrogen source (ammonium sulfate) that gives optimal growth conditions.

Protocol for growth optimization

The growth of each bacterial strain was optimized for the highest production of biomass per input gram of carbon source. Briefly, the first evening (Day 1) a glycerol stock of the K10 strain was plated on fresh LB agar plates with no 
antibiotic and incubated overnight at $37^{\circ} \mathrm{C}$. The following evening (Day 2), a $5 \mathrm{ml}$ starter culture in SPG medium supplemented with unlabeled carbon sources was inoculated with a single colony and incubated overnight at $37^{\circ} \mathrm{C}$ (i.e., 12-16 h). At the end of this incubation period (Day 3 ), the solution was pelleted at $3000 \mathrm{rpm}$ for $5 \mathrm{~min}$; the pellet was washed two times in 1x PBS and centrifuged at $3000 \mathrm{rpm}$ for $5 \mathrm{~min}$. This cell pellet was resuspended in $5 \mathrm{ml}$ of fresh SPG medium without any carbon source; $1 \mathrm{ml}$ of this resuspension was added to a $50 \mathrm{ml}$ culture in SPG medium with unlabeled carbon source and incubated at $37^{\circ} \mathrm{C}$ for $12-14 \mathrm{~h}$ with shaking at $270 \mathrm{rpm}$, making sure the $\mathrm{OD}_{600}$ did not saturate. At the end of this incubation, the solution was centrifuged, the resultant pellet washed twice in 1x PBS and the pellet was resuspended in $50 \mathrm{ml}$ fresh SPG medium without any carbon source. Then $5 \mathrm{ml}$ was added to two $500 \mathrm{ml} \mathrm{SPG} \mathrm{medium} \mathrm{containing} \mathrm{labeled}$ carbon source. About $10 \mathrm{ml}$ of labeled media was saved for resuspension of the $500 \mathrm{ml}$ culture pellet. The $500 \mathrm{ml}$ labeled culture was incubated at $37^{\circ} \mathrm{C}$ for $12 \mathrm{~h}$.

Nucleic acid digestion and cis diol affinity column purification

The isotopically enriched ribonucleotides were isolated from E. coli as described earlier (Batey et al. 1995). The cell pellet was resuspended in $20 \mathrm{ml}$ STE buffer $(0.1 \mathrm{M}$ $\mathrm{NaCl}, 10 \mathrm{mM}$ Tris, $1 \mathrm{mM}$ EDTA, $\mathrm{pH}$ 8) for two grams of frozen cells and lysed in STE with 0.5\% SDS. The cellular proteins were removed with 25:24:1 Phenol:Chloroform:Isoamyl mix. The upper aqueous layer, pooled from multiple extractions of the organic and inclusion layers, was back-extracted with an equal volume of 24:1 Chloroform:Isoamyl alcohol. The residual nucleic acids were precipitated overnight with ethanol and acetate buffer $(\mathrm{pH}$ 5.2) at $-20^{\circ} \mathrm{C}$. The cellular nucleic acids were digested with nuclease $\mathrm{P} 1$ in $15 \mathrm{mM}$ sodium acetate, $0.1 \mathrm{mM}$. $\mathrm{ZnSO}_{4}, \mathrm{pH}$ 5.2. The deoxyribonucleotides were separated from the ribonucleotides using a cis-diol boronate affinity chromatography in a $20 \times 2.5 \mathrm{~cm}$ glass column. The digested nucleic acid solution was filtered and loaded onto a boronate affinity resin (10 g of Affigel 601 from Biorad) pre-equilibrated with $1 \mathrm{M}$ TEABC at $\mathrm{pH} 9.5$ at $4^{\circ} \mathrm{C}$. The deoxyribonucleotides, salts, and other impurities were washed from the boronate column using five column volumes of $1 \mathrm{M}$ TEABC. The ribonucleotides were eluted with water acidified with $\mathrm{CO}_{2}$ and the purity of the rNMPs was verified by NMR.

\section{NMR experiments}

NMR experiments were run on a four channel Bruker Avance $600 \mathrm{MHz}$ spectrometer equipped with actively shielded z-axis gradient triple resonance probe. NMR data sets were processed and the peak positions and intensities were analyzed with Bruker's TOPSPIN 2.1. The rNMP fractions were analyzed by ${ }^{1} \mathrm{H}$ and ${ }^{13} \mathrm{C}$ NMR experiments. One dimensional (1D) ${ }^{13} \mathrm{C}$ spectra were collected with a $45^{\circ}$ and $90^{\circ}$ tip angles, and GARP (Shaka et al. 1985) ${ }^{1} \mathrm{H}$ decoupling was applied only during acquisition. 1D ${ }^{1} \mathrm{H}$ spectra were also collected without ${ }^{13} \mathrm{C}$ decoupling during acquisition. All spectra, unless indicated, were collected at $25^{\circ} \mathrm{C}$. Two-dimensional non-constant-time $\left({ }^{1} \mathrm{H},{ }^{13} \mathrm{C}\right)$ HSQC (Mueller 1979; Bodenhausen and Ruben 1980; Bax et al. 1990) were recorded to resolve ambiguities arising from overlap in the 1D spectra. Spectra requiring quantitative analysis were acquired with a long recycle delay $(5 \mathrm{~s})$ to ensure sufficient recovery of magnetization.

For the base region, the two-dimensional (2D) experiments were acquired with sweep widths of $8013 \mathrm{~Hz}$ in the ${ }^{1} \mathrm{H}$ acquisition dimension and $3322 \mathrm{~Hz}$ in the ${ }^{13} \mathrm{C}$ dimension. For each data set, 8 scans and 1024 complex points were collected in $t_{2}$ and 256 complex points were collected in $t_{1}$ using the Echo-Anti echo method (Palmer et al. 1991; Kay et al. 1992) for quadrature detection. ${ }^{13} \mathrm{C}$-GARP (Shaka et al. 1985) decoupling was applied during the acquisition period or omitted to obtain residual labeling information. Proton and carbon carrier was placed at $4.7 \mathrm{ppm}$ and $142.5 \mathrm{ppm}$ respectively. An INEPT delay of $2.5 \mathrm{~ms}$ (optimized for ${ }^{1} \mathrm{~J}_{\mathrm{HC}}=200 \mathrm{~Hz}$ for the base region and corresponding to $\left.1 /\left(2 * \mathrm{~J}_{\mathrm{HC}}\right)\right)$ was used for magnetization transfer. For the ribose region $2 \mathrm{D}$ experiments were acquired with sweep widths of $8013 \mathrm{~Hz}$ in the ${ }^{1} \mathrm{H}$ dimension and $5058 \mathrm{~Hz}$ in the ${ }^{13} \mathrm{C}$ dimension. For each data set, 8 scans and 1024 complex points were collected in $t_{2}$ and 256 complex points were collected in $t_{1}$ using the Echo-Anti echo method (Palmer et al. 1991; Kay et al. 1992) for quadrature detection. ${ }^{13} \mathrm{C}$-GARP decoupling was applied during the acquisition period. Proton and carbon carrier was placed at $4.7 \mathrm{ppm}$ and $76.5 \mathrm{ppm}$ respectively. An INEPT delay of $3.29 \mathrm{~ms}$ (optimized for ${ }^{1} \mathrm{~J}_{\mathrm{HC}}=152 \mathrm{~Hz}$ for the ribose region and corresponding to $\left.1 /\left(2 * \mathrm{~J}_{\mathrm{HC}}\right)\right)$ was used for magnetization transfer. The time domain data was zero filled in $t_{1}$ and $t_{2}$ before Fourier transformation to give a final real matrix size of $2048 \times 1024$ points.

Two- and three-bond $2 \mathrm{D}\left({ }^{1} \mathrm{H},{ }^{15} \mathrm{~N}\right) \mathrm{HSQC}$ experiments were acquired as follows. For the ${ }^{1} \mathrm{H}$ acquisition period $\left(t_{2}\right)$, sweep widths of $2761 \mathrm{~Hz}$ (4.6 ppm) were used, and for the ${ }^{15} \mathrm{~N}$ evolution period $\left(t_{1}\right)$, sweep widths of 4563.8 or $6815.2 \mathrm{~Hz}$ (75 or $112 \mathrm{ppm}$ ) were used. For each data set, 16 or 32 scans and 1024 complex points were collected in $\mathrm{t}_{2}$ and 128 complex points were collected in $\mathrm{t}_{1}$ using the Echo-Anti echo method for quadrature detection. Proton, carbon and nitrogen carrier was placed respectively at $4.7 \mathrm{ppm}, 120.0 \mathrm{ppm}$ and 202.5 (or 192) ppm. ${ }^{15} \mathrm{~N}-$ GARP decoupling (Shaka et al. 1985) was applied during the 
acquisition period, and ${ }^{13} \mathrm{C}$-GARP decoupling (Shaka et al. 1985) was also applied or omitted during the acquisition period. An INEPT delay of 15.6 or $25 \mathrm{~ms}$ (optimized for ${ }^{2} J_{\mathrm{HN}}=16$ or 20 or $25 \mathrm{~Hz}$ for the two bond coupling to the purine nitrogen and corresponding to $\left.1 /\left(2 * \mathrm{~J}_{\mathrm{HN}}\right)\right)$ was used for magnetization transfer. These delays did not affect the $\%$ level labeling prediction (see below).

Relative peak intensities were determined by integrating peaks observed with proton decoupling during acquisition only and a long recycle delay (5 s) to allow sufficient magnetization recovery for the direct carbon experiments. For the 2D experiments, all data were plotted to the same base level, level of increment and number of contour levels before peak picking and peak integration.

To simulate the effect of a medium-sized RNA, we ran non-constant time $2 \mathrm{D}{ }^{13} \mathrm{C}$ HSQC and ${ }^{13} \mathrm{C}$ TROSY (Meissner et al. 1998; Pervushin et al. 1998; Czisch and Boelens 1998; Weigelt 1998; Rance et al. 1999; Zhu et al. 1999; Schulte-Herbrüggen and Sorensen 2000) on a mixture of all four nucleotides dissolved in $95 \% \mathrm{w} / \mathrm{w}$ perdeuterated glycerol (Cambridge Isotope Labs, Andover, $\mathrm{MA})$ at $30^{\circ} \mathrm{C}$.

\section{Results and discussion}

The ability to transcribe RNA (or DNA) labeled with various isotopes, such as ${ }^{13} \mathrm{C},{ }^{15} \mathrm{~N}$ and ${ }^{2} \mathrm{H}$, has enabled the application of heteronuclear multi-dimensional NMR techniques to characterize the structure and dynamics of interesting biological RNA molecules (D'Souza et al. 2004; Gumbs et al. 2006; Lu et al. 2010). Unsurprisingly a number of research groups have developed and continue to develop techniques for the biosynthetic production of isotopically labeled nucleotides. Some produce uniformly labeled nucleotides from E. coli (Nikonowicz et al. 1992; Michnicka et al. 1993), M. methylotrophus (Batey et al. 1992), or Methylophilus extorquens (Hines et al. 1994). Others produce site specifically labeled nucleotides from E.coli (Latham et al. 2005; Johnson et al. 2006), and still others produce these labels using the pentose phosphate and de novo purine synthetic pathways (Schultheisz et al. 2008). Similar methods for the production of uniform isotopically labeled deoxynucleosides have been proposed (Zimmer and Crothers 1995; Louis et al. 1998; Masse et al. 1998; Werner et al. 2001; Nelissen et al. 2009). Previously, ${ }^{13} \mathrm{C}$-formate added to an unlabeled glucose minimal medium enabled selective labeling of purine $\mathrm{C} 8$ positions (Latham et al. 2005), and use of E. coli deficient in the G6PDH gene enabled the site-labeling of pyrimidine $\mathrm{C} 5$ or C6 positions as well as various ribose carbon positions (Johnson et al. 2006). To our knowledge, no published reports have shown the combined advantages of both:
Grow E. coli strain $\mathrm{K} 10$ on ${ }^{13} \mathrm{C}$-labeled glycerol with ${ }^{13} \mathrm{C}$-formate to overcome the limitations of each separate method. Using $2 \mathrm{~g}$ of ${ }^{13} \mathrm{C}$-2-glycerol and $0.7 \mathrm{~g}$ of $\mathrm{NH}_{4}\left(\mathrm{SO}_{4}\right)_{2}$ as carbon and nitrogen sources, we obtained $4 \mathrm{~g}$ of wet cell pellet for a liter of $E$. coli K10 cell culture. Addition of $0.2 \mathrm{~g}$ of ${ }^{13} \mathrm{C}$ formate to this medium was sufficient to label sites not otherwise labeled. Yields of up to $66 \mathrm{mg}$ of rNMPs and $13 \mathrm{mg}$ of dNMPs obtained are comparable to previous reports of labeling (Batey et al. 1992). To obtain optimal yields it is important to use minimal media other than M9. As reported by others, M9 is inferior to other buffers (Paliy and Gunasekera 2007; Dayie unpublished).

Incorporation of ${ }^{13} \mathrm{C}$ into ribose ring of nucleotides using the pentose phosphate pathway

To place our results within the context of the metabolic pathways in E. coli for nucleotide metabolism, we present a brief overview of some of the steps in glycolysis, gluconeogenesis and the tricarboxylic acid (TCA) cycle. Details can be found in standard textbooks (Voet et al. 2008; Nelson and Cox 2008).

Glycerol enters the metabolic cycle as dihydroxyacetone phosphate (DHAP) and equilibrates rapidly with glyceraldehyde-3-phosphate (GA3P) by the action of triosephosphate isomerase (TIM). From this point in the cycle, GA3P can be converted to ribose-5-phosphate (R5P) via gluconeogenesis using the oxidative pentose phosphate pathway (oPPP; Fig. 1). Alternatively GA3P and fructose6-phosphate (F6P) can also be converted to R5P via the action of transketolase and transaldolase in the reverse of the non-oxidative PPP (noPPP; Fig. 1). In wild type E. coli both the oPPP and noPPP can be operative and the partitioning of the carbon flux through these two pathways leads to scrambling of labels in the ribose ring. However, for strains defective in the oPPP such as the K10 E. coli strain, most of the carbon flux is re-routed through the reverse noPPP via the action of transketolase and transaldolase (Edwards and Palsson 2000; Zhao et al. 2004; Nicolas et al. 2007). Assuming auxiliary biosynthetic pathways contribute negligibly to the central pathway, a ${ }^{13} \mathrm{C}$-label at the central C-2 carbon of glycerol would lead to isotopic enrichment for $\left[2,4-{ }^{13} \mathrm{C}_{2}\right]$ ribose and $\left[4-{ }^{13} \mathrm{C}\right]$ ribose in a $2: 1$ ratio (Fig. 1), and no label is expected at the 1, 3 or 5 ribose carbon positions (Johnson et al. 2006).

Exogenous formate can enter the metabolic cycle by exchanging the carboxyl group of pyruvate by consuming acetyl-CoA (Thauer et al. 1972; Knappe et al. 1974) by the reversible action of pyruvate formate lyase (Kirkpatrick et al. 2001). This modified pyruvate may populate gluconeogenesis intermediates such as GA3P and F6P for use in the reverse of the noPPP. At the moment, the effect of 
Fig. 1 Major metabolic pathways involved in the production of nucleic acid nucleotides, including key steps in glycolysis, gluconeogenesis and one pass through the tricarboxylic (TCA) cycle. For E. coli carrying the $z w f$ genotype (glucose 6-phosphate dehydrogenase (G6PDH) mutant), the oxidative branch of the pentose phosphate pathway is disabled (indicated by an $X$ through the orange arrow) such that most of the carbon fluxes are shunted through the reverse non-oxidative pentose phosphate pathway (noPPP). Atom labels for the terminal $(1,3)$ carbons (magenta and thin circle) and central (2) carbon (cyan and thick circle) of glycerol are highlighted. Positions that are enriched due to the presence of ${ }^{13} \mathrm{CO}_{2}$ (as bicarbonate) in the growth medium are shown with an encircled $X$, but this is lost through the first and subsequent pass through the TCA cycle. Pyrimidine bases derived from oxaloacetate (OAA) produced by carboxylation of phosphoenolpyruvate (PEP) is shown via the aspartate intermediate. This OAA is used as a substrate in the first and subsequent rounds of the TCA cycle to produce OAA with a pair of different labeling schemes as products due to the symmetric nature of the TCA cycle intermediate succinate. If $\left[2-{ }^{13} \mathrm{C}\right]$ glycerol is used $\mathrm{C}^{\alpha}$ or $\mathrm{C}^{\beta}$ or $\mathrm{C}^{\gamma}$ or $\mathrm{C}^{\beta}$ and $\mathrm{C}^{\gamma}$ but not all three positions are labeled simultaneously. Similarly the labeling pattern of purines from glycine (Gly) derived from 3phosphoglycerate (3PG) are shown such that if

$\left[2-{ }^{13} \mathrm{C}\right]$ glycerol is used only the $\mathrm{C}^{\alpha}$ position of Gly and therefore $\mathrm{C} 5$ position of the purine ring is labeled. The use of GA3P and F6P in the reverse of the nonoxidative PPP produces ribose labeled at the 2,4 and 4 positions if $\left[2-{ }^{13} \mathrm{C}\right]$ glycerol is used

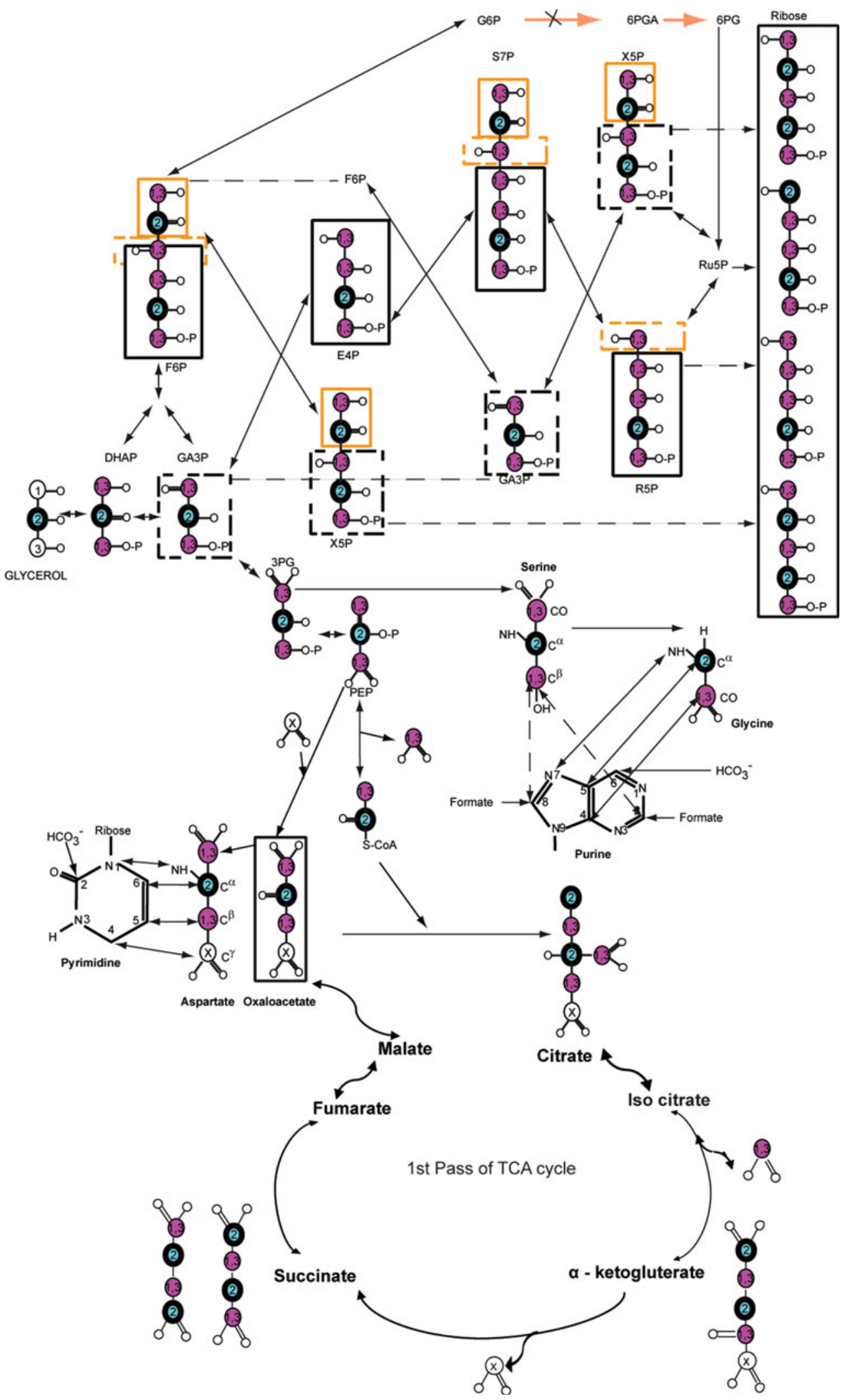

increasing the level of enrichment at the ribose carbon positions predicted to have no label using the central metabolic pathway. exogenous formate on $E$. coli growth remains poorly characterized and poorly understood. Nonetheless, as we show later, addition of formate has an unexpected effect of 
Incorporation of ${ }^{13} \mathrm{C}$ into base ring of nucleotides via the tricarboxylic acid cycle, glycolysis, and gluconeogenesis

Various metabolic precursors make amino acids from which nucleotide bases are synthesized (Fig. 1). 3-phosphoglycerate (3PG) gives rise to serine (Ser) and glycine (Gly), and oxaloacetate (OAA) gives rise to aspartic acid (Asp). In turn, the six-membered Pyr ring is constructed from four atoms of Asp such that the $\mathrm{NH}$ amide group, the $\mathrm{C}^{\alpha}-\mathrm{C}^{\beta}$ - and $\mathrm{C}^{\gamma}$-carbon positions of Asp becomes the $\mathrm{N} 1$,
C6, C5 and C4 ring atoms respectively of Pyr (Fig. 1). The $\mathrm{N} 3$ and $\mathrm{C} 2$ positions are derived from glutamine amide and bicarbonate pools respectively. The bicarbonate single carbon pool is diluted by ${ }^{12} \mathrm{C}$ carbons such that labeling at the Pyr C2 position is random at low levels unless this carbon pool is augmented with ${ }^{13} \mathrm{C}$-bicarbonate (Lundström et al. 2007). The larger Pur ring atoms $C 2$ and $C 8$ also derive from the formate pool. Thus, adding ${ }^{13} \mathrm{C}$-formate to the growth media is again expected to increase the level of ${ }^{13} \mathrm{C}$ isotopic enrichment at the $\mathrm{C} 2$ and $\mathrm{C} 8$ sites. The amide group, the $\mathrm{C}^{\alpha}$ - and carbonyl (CO)-carbon positions of

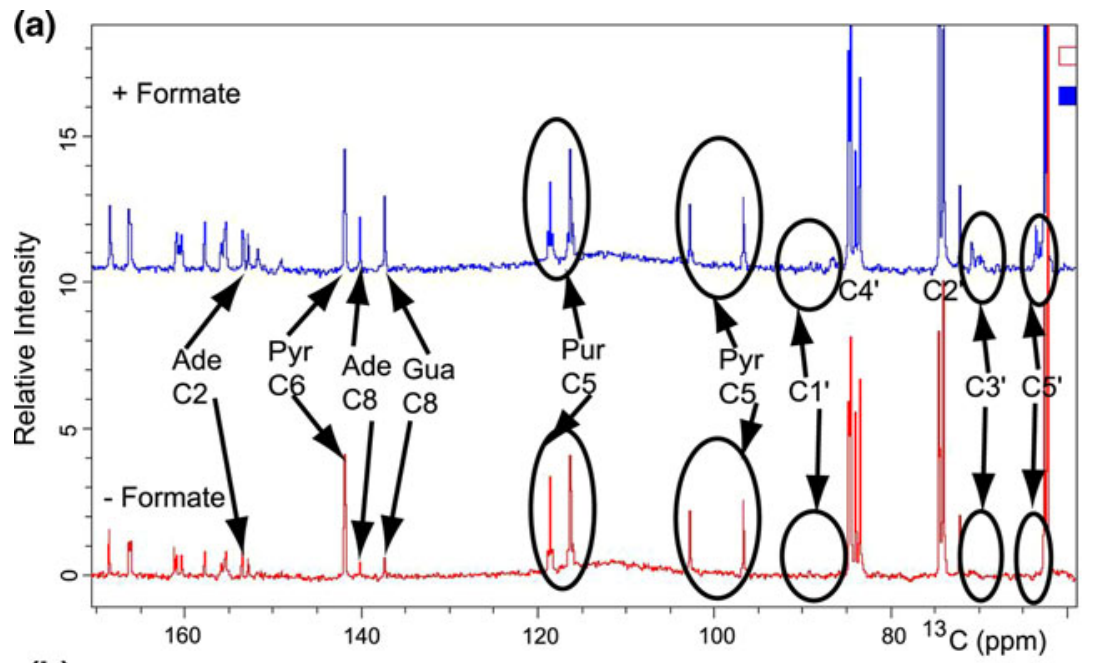

(b)

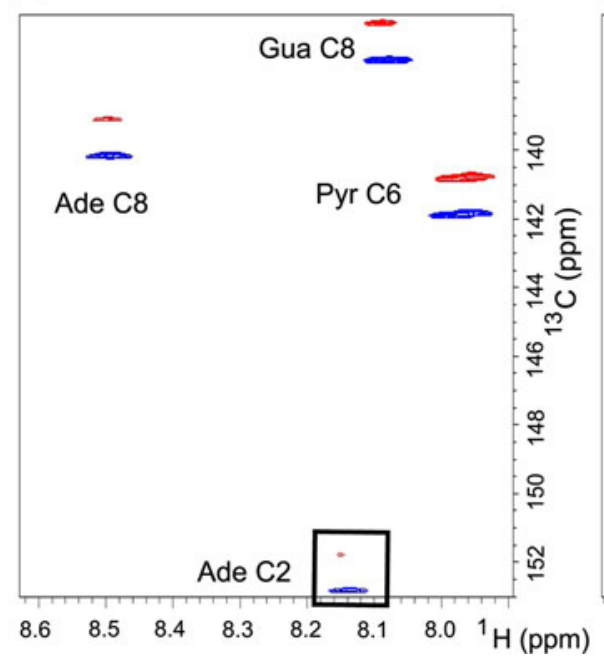

(c)

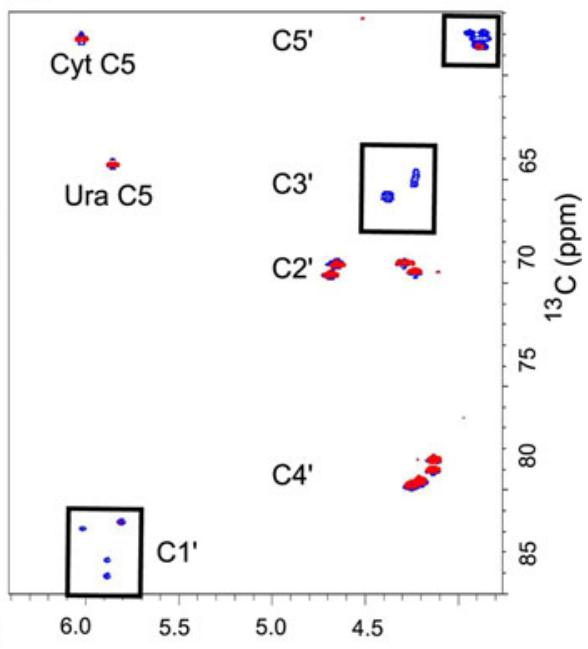

Fig. 2 Increased level of labeling in K10 without (red) and with (blue) ${ }^{13} \mathrm{C}$-formate in a ${ }^{13} \mathrm{C}$-2-glycerol background. The experiments were performed on mixtures of the four rNMPs isolated from the K10 bacterial culture. a Direct carbon detection 1D spectrum showing all the carbon positions for nucleotides labeled with glycerol and no formate (bottom, red) or glycerol with formate (top, blue). A long recycle delay of $5 \mathrm{~s}$ were used to allow for sufficient magnetization recovery and proton decoupling was limited to the acquisition period only. The level of enrichment at the adenine (Ade) and guanine (Gua) $\mathrm{C} 8$ positions increases by spiking with ${ }^{13} \mathrm{C}$-labeled formate. The $\mathrm{C}^{\prime}$ region has an impurity that resonates in a distinct region in the $2 \mathrm{D}$ spectrum. b 2D non-constant time HSQC spectrum of a mixture all four labeled rNMPs showing the protonated base region. For ease of comparison the spectrum obtained without labeled formate (red contours) are displaced vertically relative to the formate labeled spectrum (blue contours). c 2D non-constant time HSQC spectrum of a mixture of all four labeled nucleotides showing the ribose region. The cytosine (Cyt) and Uracil (Ura) C5 resonances at $96.67 \mathrm{ppm}$ and $102.69 \mathrm{ppm}$ respectively are folded into the spectrum. The boxed resonances highlight the increased labeling level seen for $\mathrm{Cl}^{\prime}, \mathrm{C}^{\prime}$ and $\mathrm{C}^{\prime}$ with spiking the growth medium with ${ }^{13} \mathrm{C}$-labeled formate 
glycine (Gly) become the N7, C5 and C4 ring atoms respectively (Fig. 1). We use Fig. 1 as a framework for interpreting some of our results with $E$. coli strain K10.

Label incorporation by E. coli strain K10 in the absence of ${ }^{13} \mathrm{C}$-labeled formate

E. coli strain $\mathrm{K} 10$ grown in ${ }^{13} \mathrm{C}$-2-glycerol media in the absence of labeled formate has varied labeling patterns in both ribose and base moieties (Fig. 2; Table 1). The ribose ring is labeled exclusively at the $\mathrm{C} 2^{\prime}$ and $\mathrm{C}^{\prime}$ positions $(>80 \%$ label) as expected for the metabolic carbon flux going mostly through the transketolase/transaldolase branch of the noPPP. Little labeling is observed at $\mathrm{C}^{\prime}$, and the negligible carbon-carbon splitting at $\mathrm{C}^{\prime}$ and $\mathrm{C}^{\prime}$ positions (Fig. $2 \mathrm{a}-\mathrm{c}$ ) further bears out the prediction from the analysis of the metabolic pathway. However, some residual labeling is observed at the $\mathrm{C}^{\prime}$ $(\sim 1 \%)$ and $\mathrm{C}^{\prime}(\sim 1 \%)$ positions. The isotopic enrichment level at $\mathrm{C}^{\prime}$ and $\mathrm{C}^{\prime}$ increases in the presence of formate (as discussed further below). This residual labeling suggests gluconeogenesis might be significant in this mutant when grown on glycerol. Alternatively, a fraction $(\sim 7 \%)$ of serine molecules is predicted to be produced by a bypass of the disabled G6PDH in the zwf mutant (Fischer and Sauer 2003). Further studies such as metabolic flux analysis using gas chromatography-mass spectrometry (GC-MS) and NMR spectroscopy are needed to address the origin of these residual labels fully (Fischer and Sauer 2003).

For the base atoms, both the protonated C5 and C6 carbon positions of Pyr are substantially labeled at $\sim 45 \%$ close to the expected $50 \%$ level, whereas the protonated $\mathrm{C} 2$ and $\mathrm{C} 8$ carbon positions of Pur are labeled at a lower level ( 10-14\%; Fig. 2a-b). The C5 and C6 pyrimidine sites are constructed entirely from Asp which in turn is generated from OAA either by direct carboxylation of PEP or from the TCA cycle. Using $\left[2-{ }^{13} \mathrm{C}\right]$-glycerol as the sole carbon source, Asp formed from carboxylation of PEP (using cellular bicarbonate breakdown to $\mathrm{CO}_{2}$ by pyruvate carboxylase) is expected to be $100 \%$ enriched exclusively at the $\mathrm{C}^{\alpha}$ position or equivalently the $\mathrm{C} 6$ position of Pyr. A single pass through the TCA cycle leads, because the TCA cycle metabolite succinate is symmetric, to an equal probability of labeling either the $\mathrm{C}^{\alpha}$ or the $\mathrm{C}^{\beta}$ position. But both positions cannot be labeled

Table $1{ }^{13} \mathrm{C}$ enrichment levels at various carbon positions within ribonucleotides using $\left[2-{ }^{13} \mathrm{C}\right]$-glycerol with and without ${ }^{13} \mathrm{C}$-labeled formate as carbon sources using E. coli strain K10

\begin{tabular}{lll}
\hline Carbon position labeled & ${ }^{13}$ C-Carbon Source: 2-Glycerol only & \\
\hline Purine $^{\mathrm{a}}$ & & ${ }^{13}$ C-Carbon Source: 2-Glycerol and Formate \\
Ade C2 & $13.6 \pm 2.7$ & $26.4 \pm 2.0$ \\
Ade C8 & $10.0 \pm 1.0$ & $35.8 \pm 1.8(35.8)^{\mathrm{b}}$ \\
Gua C8 & $10.0 \pm 1.0$ & $37.8 \pm 1.5(39.8)^{\mathrm{b}}$ \\
Pyrimidine ${ }^{\mathrm{a}}$ & & \\
C5 & $44.7 \pm 1.2$ & $49.0 \pm 2.9$ \\
C6 & $45.7 \pm 1.4$ & $42.0 \pm 5.5$ \\
Ribose & & \\
C1 $^{\prime}$ & $0.7 \pm 0.3$ & $3.0(5.0 \pm 1.9)^{\mathrm{d}}$ \\
C2 $^{\prime}$ & $90 \pm 10$ & $90 \pm 10$ \\
C3 $^{\prime}$ & $<1$ & $8.8 \pm 1.5$ \\
C4 $^{\prime}$ & $90 \pm 10$ & $90 \pm 10$ \\
C5 $^{\prime}$ & $0.7 \pm 0.3$ & $10.6 \pm 0.9$ \\
\hline
\end{tabular}

${ }^{\text {a }}$ The percentage label (Plabel) is calculated as the ratio of the sum of the intensities of satellite peaks to the sum of the intensities of the satellite and center peaks using the 2-bond ${ }^{15} \mathrm{~N}$ HSQC without ${ }^{13} \mathrm{C}$ decoupling during acquisition; in Fig. $3 \mathrm{c}$ the satellite peaks are labeled I and II, the center peak is labeled III and PLabel $=(\mathrm{I}+\mathrm{II}) /(\mathrm{I}+\mathrm{II}+\mathrm{III})$

b The numbers in parenthesis are calculated as the ratio of the sum of the intensities of satellite peaks to the sum of the intensities of the satellite and center peaks from the $1 \mathrm{D}{ }^{1} \mathrm{H}$ spectrum acquired without ${ }^{13} \mathrm{C}$ decoupling

${ }^{\mathrm{c}}$ For the ribose region the degree of labeling is estimated using the percentage labeling relative to the $\mathrm{C} 2^{\prime}$ and $\mathrm{C} 4^{\prime}$ peak intensities, and each relative percentage labeling is scaled by $97 \%$, assuming $\mathrm{C} 2^{\prime}$ and $\mathrm{C} 4^{\prime}$ positions are labeled at $97 \%$ level

${ }^{d}$ The numbers in parenthesis are derived from the ratio of the sum of the intensities of satellite peaks to the sum of the intensities of the satellite and center peaks using the 2-bond ${ }^{15} \mathrm{~N}$ HSQC without ${ }^{13} \mathrm{C}$ decoupling during acquisition 
simultaneously in the same molecule. Thus either the C5 or the $\mathrm{C} 6$ position of Pyr is labeled at 50\% maximum enrichment with no undesired C5-C6 labeled pair. In the second pass through the TCA cycle, the $\mathrm{C} 4$ carbon is also labeled to a maximum value of $25 \%$; subsequent passes through the cycle will reduce even further this level of labeling at $\mathrm{C} 4$. Those molecules labeled at $\mathrm{C} 4$ are predicted to have no label at either the $\mathrm{C} 5$ or the $\mathrm{C} 6$ position. Thus there should be no coupling between $\mathrm{C} 4$ and $\mathrm{C} 5$ or C4 and C6.

The Pur $\mathrm{C} 2$ and $\mathrm{C} 8$ positions arise from metabolic breakdown product of formate and the Pur C6 and Pyr C2 atomic positions arise from bicarbonate byproduct. As a result these sites are expected to be randomly labeled at very low levels in the absence of spiking the growth media with ${ }^{13} \mathrm{C}$-labeled formate or bicarbonate.

Label incorporation by E. coli strain K10

in the presence of ${ }^{13} \mathrm{C}$-labeled formate

Addition of ${ }^{13} \mathrm{C}$-formate leads to increased labeling in both ribose and base moieties (Fig. 2; Table 1). In the ribose ring, labeling increases for the $\mathrm{C}^{\prime}(3-5 \%), \mathrm{C}^{\prime}$ $(\sim 9 \%)$ and $\mathrm{C}^{\prime}(\sim 11 \%)$ positions without introducing significant carbon-carbon coupling at these positions $\left(\mathrm{Cl}^{\prime}\right.$, $\mathrm{C}^{\prime}, \mathrm{C}^{\prime}$ and $\mathrm{C}^{\prime}$; Fig. 2). These labeling efficiencies can be estimated from a comparative analysis of the 1D carbon spectra of uniformly labeled rNMPs and the site specific labeled rNMPs derived from the K10 bacteria culture. As discussed below a different method using twobond ${ }^{15} \mathrm{~N}$ HSQC gives comparable results. Nonetheless it is unexpected that in the face of $>80 \%$ labeling of $\mathrm{C}^{\prime}$ and $\mathrm{C} 4^{\prime}, \mathrm{C}^{\prime}-\mathrm{C}^{\prime}$ and $\mathrm{C}^{\prime}-\mathrm{C} 2^{\prime}$ splittings are not observed. Analysis of the reverse noPPP suggests oxaloacetate generated by several passes through the TCA cycle will populate a pyruvate intermediate that could ultimately label $\mathrm{R} 5 \mathrm{P}$ at the $\mathrm{C}^{\prime}$ and $\mathrm{C}^{\prime}$ positions with exclusion of labels at $\mathrm{C} 2^{\prime}$ and $\mathrm{C} 4^{\prime}$ positions in the same molecule. This is in addition to the expected labels at $\mathrm{C}^{\prime}{ }^{\prime}$ and $\mathrm{C}^{\prime}{ }^{\prime}$ without adjacent labels at $\mathrm{C}^{\prime}$ and $\mathrm{C}^{\prime}$ in the same molecule. Alternately a bypass of the disabled G6PDH in the zwf mutant catalyzed by the perisplasmic glucose dehydrogenase (Fischer and Sauer 2003) could potentially produce a label at the $\mathrm{C}^{\prime}$ and $\mathrm{C}^{\prime}$ without any coupled adjacent labels. Further study using GC-MS and NMR are needed to resolve this empirical observation of label at the $\mathrm{C}^{\prime}$ and $\mathrm{C}^{\prime}$ positions.

A similar increase in the labeling level is observed in the base region on addition of labeled formate to the ${ }^{13} \mathrm{C}-2$ glycerol media. Significant isotopic enrichment of the C8 ( $\sim 40 \%)$ and $\mathrm{C} 2(\sim 26 \%)$ carbon positions of the Pur ring are observed, but those at the C6 and C5 Pyr positions remain unchanged (Fig. 2b; Table 1).
Estimation of the degree of ${ }^{13} \mathrm{C}$ isotope incorporation using two- and three-bond ${ }^{15} \mathrm{~N}$ HSQC

Finally, addition of labeled ${ }^{15} \mathrm{~N}$-ammonium sulfate enables high level labeling of the aromatic nitrogens and estimation of the degree of ${ }^{13} \mathrm{C}$ isotope incorporation. The level of ${ }^{13} \mathrm{C}$ labeling efficiency is usually estimated using $1 \mathrm{D}{ }^{1} \mathrm{H}$ or natural abundance ${ }^{13} \mathrm{C}$ carbon spectra. Lack of a central singlet peak and the presence of doublet satellite peaks indicate close to $100 \%$ labeling efficiency. Absence of the doublet satellite peaks and the presence of a dominant central peak are then taken as lack of ${ }^{13} \mathrm{C}$ incorporation. Thus by comparing the intensity of each ${ }^{13} \mathrm{C}$ satellite peak to the intensity of the center peak, the labeling efficiency is readily estimated. This 1D approach works well for single nucleotides that have no spectral overlap. For a mixture of the four rNMPs extracted from the K10 bacteria culture, there is significant overlap in both the base and ribose regions. For example Ade $\mathrm{H} 1^{\prime}$ (6.02 ppm) overlaps completely with Cyt H5 (6.02 ppm) in the proton chemical shift region, and Ura $\mathrm{H}^{\prime}{ }^{\prime}(5.90 \mathrm{ppm})$ overlaps with $\mathrm{Cyt} \mathrm{H}^{\prime}$ (Fig. 2c). This overlap problem limits the usefulness of the 1D method. Long range (two- and three-bond) protonnitrogen correlations in ${ }^{15} \mathrm{~N}-\mathrm{HSQC}$ spectra make it possible to estimate the labeling efficiency of the $\mathrm{C} 2$ and $\mathrm{C} 8$ carbon sites within the Pur aromatic ring, the $\mathrm{C} 5$ and $\mathrm{C} 6$ carbon sites within the Pyr aromatic ring and the Pur $\mathrm{Cl}^{\prime}$ carbon site (Fig. 3). Relaxation properties and transfer efficiencies are different for long range and one-bond magnetization transfers, and so it is important to validate the use of the long range ${ }^{15} \mathrm{~N}$-HSQC method to estimate the level of ${ }^{13} \mathrm{C}$ incorporation. The $1 \mathrm{D}$ slices from the $2 \mathrm{D}{ }^{2} \mathrm{~J}_{\mathrm{HN}} \mathrm{HSQC}$ spectra (Fig. 3d) overlay completely with the $1 \mathrm{D}{ }^{1} \mathrm{H}$ spectrum (Fig. 3c), suggesting the percentage label can be estimated using either the 2D or 1D experiment, but the 2D is preferable in case of overlap. With this experiment one can correlate the $\mathrm{H} 2$ proton resonances to the $\mathrm{N} 1$ and $\mathrm{N} 3$ nitrogen positions in the adenine (Ade) ring, and also the $\mathrm{H} 8$ proton resonances to the N7 and N9 nitrogen positions in the Pur ring (Fig. 3b). By omitting the carbon decoupling field during the proton acquisition period, the proton resonances are split by the directly attached ${ }^{13} \mathrm{C}$ atom $(\mathrm{C} 2$ or C8) into a doublet (Fig. 3a-b). Using this method, the ${ }^{1} \mathrm{~J}_{\mathrm{CH}}$ coupling constants measured for uniformly labeled AMP, CMP, UMP, and GMP are in excellent agreement with previous reported measurements. For uniformly ${ }^{13} \mathrm{C} /{ }^{15} \mathrm{~N}$-labeled AMP and GMP, the 2D method, in excellent agreement with the $1 \mathrm{D}{ }^{1} \mathrm{H}$ method, gives $98.9 \%$ ${ }^{13} \mathrm{C}$ isotopic enrichment at the $\mathrm{C} 8$ positions. As expected, each of the $\mathrm{H} 2$ and $\mathrm{H} 8$ proton resonance is split into a doublet with little central peak in the acquisition dimension (Fig. 3a). As the level of ${ }^{13} \mathrm{C}$ isotopic enrichment decreases from 100 to $0 \%$, each doublet gives rise to a central singlet. 
(a)

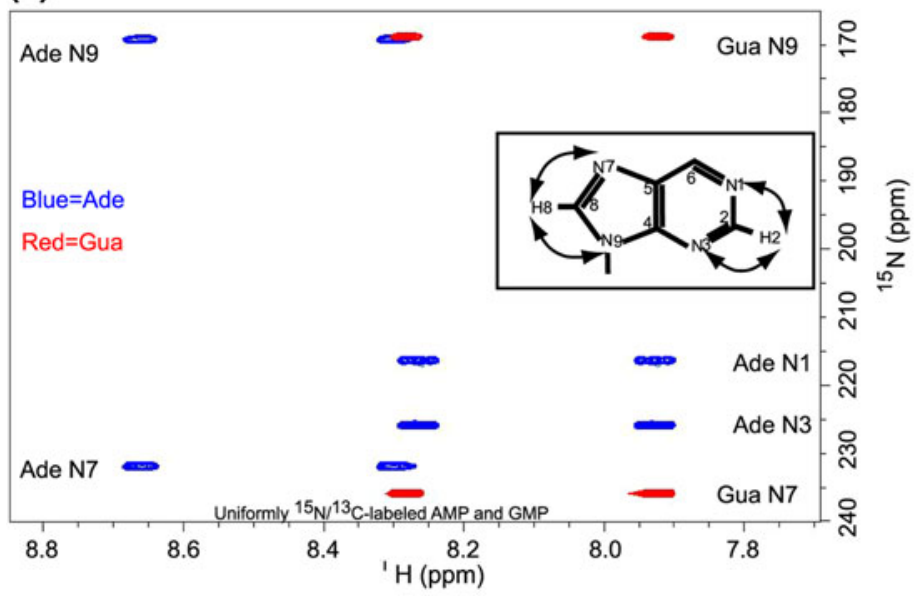

(b)

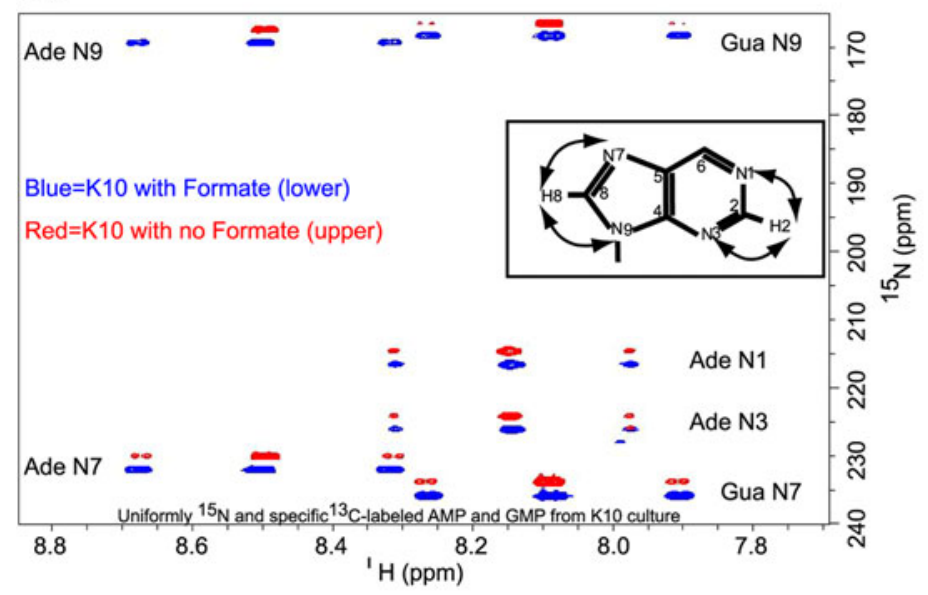

(c)

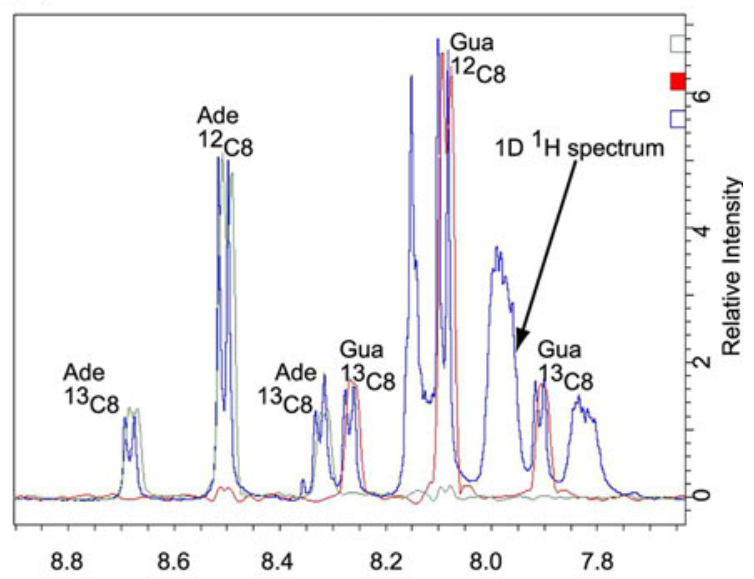

(d)

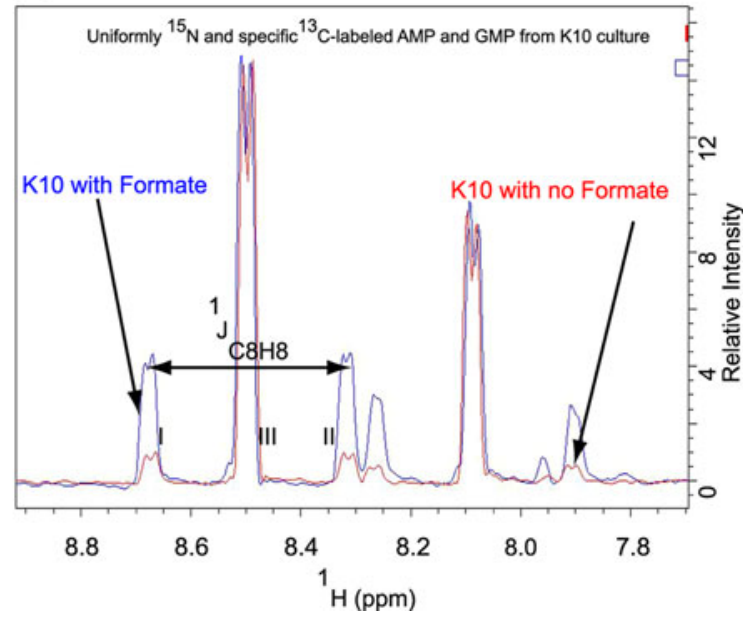

Fig. 3 Estimation of $\mathrm{C} 2$ and $\mathrm{C} 8-{ }^{13} \mathrm{C}$ labeling efficiency using twoand three-bond ${ }^{15} \mathrm{~N}-\mathrm{HSQC}$ experiment without carbon decoupling during acquisition. The $2 \mathrm{D}{ }^{1} \mathrm{H}-{ }^{15} \mathrm{~N}$ HSQC spectra depict H8-N7/N9 crosspeaks for Ade and Gua and H2-N1/N3 correlations for Ade. At each N1 and N3 nitrogen position a singlet is observed for the $\mathrm{H} 2$ proton at $8.14 \mathrm{ppm}$ if the $\mathrm{C} 2$ carbon is unlabeled and a doublet if $\mathrm{C} 2$ carbon is ${ }^{13} \mathrm{C}$-labeled due to the large one bond ${ }^{1} \mathrm{H}_{-}{ }^{13} \mathrm{C}$ coupling of $\sim 202 \mathrm{~Hz}$. Similarly at each N7 and N9 nitrogen position a singlet is observed for the $\mathrm{H} 8$ proton at $8.5 \mathrm{ppm}$ (for Ade) and $8.08 \mathrm{ppm}$ (for Gua) if $\mathrm{C} 8$ is unlabeled and a doublet if $\mathrm{C} 8$ is ${ }^{13} \mathrm{C}$-labeled due to the large one bond ${ }^{1} \mathrm{H}_{-}{ }^{13} \mathrm{C}$ coupling of $\sim 215 \mathrm{~Hz}$. Thus the ratio of each satellite peak to the central peak gives a good estimate of the degree of ${ }^{13} \mathrm{C}$ - labeling. a The $2 \mathrm{D}^{2} \mathrm{~J}_{\mathrm{HN}} \mathrm{HSQC}$ spectra for uniformly labeled NMPs (AMP, red; GMP, blue) are superimposed. The inset shows the observable long range ${ }^{1} \mathrm{H}_{-}{ }^{15} \mathrm{~N}$ correlations in the purine ring. b $2 \mathrm{D}$ ${ }^{2} J_{\mathrm{HN}}$ HSQC spectra for the mixture of four rNMPs obtained from the K10 bacterial culture are superimposed (the spectrum obtained

Analyses of the multiplet pattern of the four labeled nucleotides derived from the K10 bacteria cultures facilitated the estimation of the degree of isotopic incorporation. In the absence of formate, the level of enrichment was $\sim 10 \%$ for the Pur C8 and $\sim 14.0 \%$ for the Pur C2. In the presence of formate the level of enrichment increases to $\sim 38 \%$ for Pur C8 and $\sim 28 \%$ for Ade C2 (Table 1). without labeled formate, red contours and upper; formate labeled spectrum, blue contours and lower). The $\mathrm{H} 2$ protons and $\mathrm{N} 1$ and $\mathrm{N} 3$ nitrogen atoms and $\mathrm{H} 8$ protons and the $\mathrm{N} 7$ atoms in nucleotides labeled using $\mathrm{K} 10$ with formate in a ${ }^{13} \mathrm{C}$-2-glycerol background are depicted. The carbon decoupling field is turned off during acquisition. c The aromatic region of all 4 rNMPs extracted from K10 cultures. The ${ }^{1} \mathrm{H}$ spectrum with no ${ }^{13} \mathrm{C}$-decoulpling during acquisition (blue) is superimposed on 1D slices of the rows corresponding to the nitrogen chemical shifts of Ade N7 (green) and Gua N7 (red; see Fig. 3b). The 1D slices from the $2 \mathrm{D}^{2} \mathrm{~J}_{\mathrm{HN}}$ HSQC spectra overlay completely with the proton spectrum, suggesting the percentage label can be estimated using either the $2 \mathrm{D}$ or $1 \mathrm{D}$ experiment, but the $2 \mathrm{D}$ is preferable in case of overlap. d 1D section of the Pur N7 position (see Fig. 3b) is depicted for labeled rNMPs without formate (red) and with formate (blue). The satellite peaks are labeled I and II, and the center peak is labeled III

Applications of selective labels for NMR study of nucleic acids

High levels of isotopic enrichment lead to considerable direct one-bond scalar couplings and residual dipolar couplings from adjacent carbons yielding complex spectra for macromolecules. These deleterious consequences can 
negate the benefits of uniform labeling for monitoring RNA-ligand interactions, assignment of resonances and structural characterizations, to name only a few. For example, spectral resolution is degraded and transfer of magnetization through multiple pathways can attenuate the resultant signal. Preparation of samples lacking ${ }^{13} \mathrm{C}-{ }^{13} \mathrm{C}$ one-bond coupled spin pairs is thus critical for reducing spectral complexity and improving spectral resolution for multidimensional NMR experiments for assignment and structure determination of RNAs. Figure 4 illustrates the negative effect of coupling in a uniformly labeled sample, even in the ideal case of four nucleotides with minimum overlap. For example, in the uniformly labeled nucleotides, the $\mathrm{C} 2^{\prime}$ and $\mathrm{C} 4^{\prime}$ positions form a doublet of a doublet arising from the splitting of $\mathrm{C} 2^{\prime}$ by $\mathrm{C} 1^{\prime}$ and $\mathrm{C} 3^{\prime}$ and the splitting of $\mathrm{C}^{\prime}$ by $\mathrm{C}^{\prime}$ and $\mathrm{C}^{\prime}$ (Fig. $4 \mathrm{a}-\mathrm{b}$ ). These couplings give rise to a triplet at both positions instead of the singlet obtained using the site specific labeling (Fig. 4). These $\mathrm{C}^{\prime}$ and $\mathrm{C}^{\prime}{ }^{\prime}$ regions of the HSQC spectra demonstrate the nearly three-fold increase in the number of resolved resonances due to the site specific labeling. Similarly $\mathrm{C}^{\prime}$ and $\mathrm{C}^{\prime}$ positions form a doublet arising from the splitting of $\mathrm{C}^{\prime}$ by $\mathrm{C} 2^{\prime}$ and the splitting of $\mathrm{C}^{\prime}$ by $\mathrm{C} 4^{\prime}$
(Fig. 4c-d). The new site specific labels again result in a nearly two-fold increase in the number of resolved resonances in the $\mathrm{C}^{\prime}$ and $\mathrm{C}^{\prime}$ regions using non-constant time HQSC experiments.

Even though these unwanted splittings can be removed using constant time (Bax et al. 1979; Bax and Freeman 1981; Grzesiek and Bax 1992; van de Ven and Philippens 1992) or adiabatic band selective decoupling during the carbon evolution period (Kupce and Wagner 1996; Brutscher et al. 2001; Dayie 2005), both solutions to the splitting problem are unsatisfactory. Use of constant time evolution limits considerably the acquisition time that can be used to obtain adequate resolution, and the long constant-time delay needed for improved resolution typically leads to significant signal loss for medium-sized to large RNA molecules (Dayie 2005). Similarly, use of band selective decoupling means the sites decoupled are not available for analysis. For example, selectively decoupling $\mathrm{C} 2$ ' during carbon evolution precludes its observation. The selective labeling presented here removes both of these complications. A very important problem in NMR of nucleic acids is monitoring how nucleic acids interact site specifically with their ligands. High quality uncluttered (a)

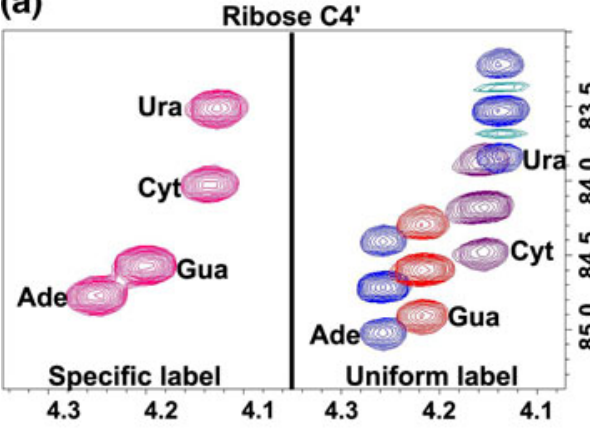

(c)

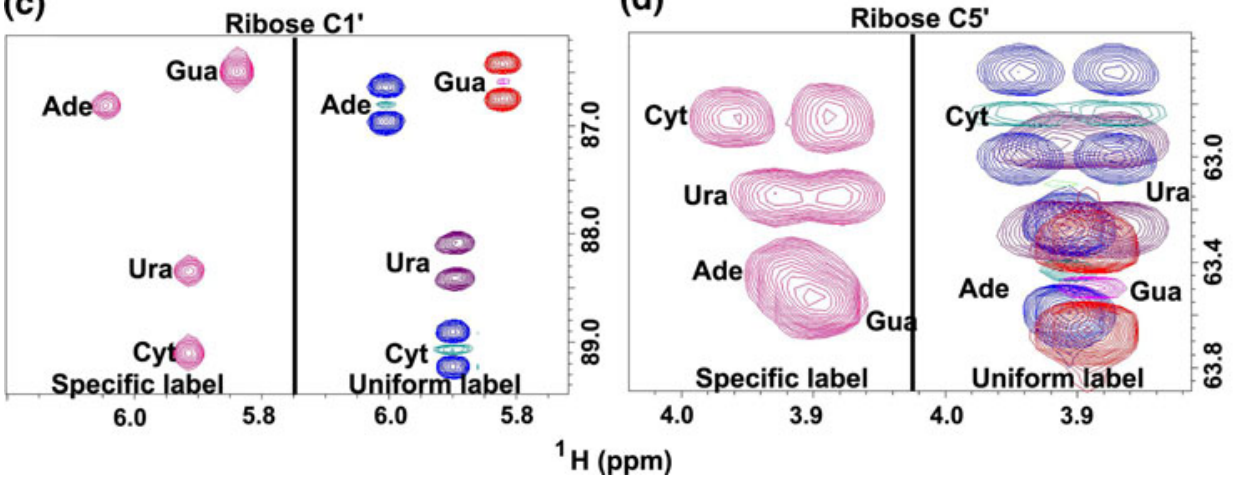

(b)

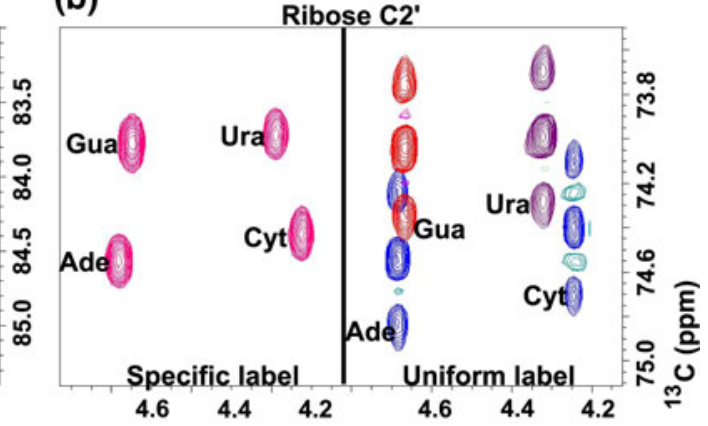

(d)

$\mathrm{GMP}=$ red, $\mathrm{CMP}=$ blue and $\mathrm{UMP}=$ purple. Note how the uniformly labeled rNMPs suffer from multiplet splitting absent in the new labels. a Ribose $\mathrm{C}^{\prime}$, b Ribose $\mathrm{C}^{\prime}$, c Ribose $\mathrm{C}^{\prime}$ and d Ribose $\mathrm{C}^{\prime}$. The resonances from each of the four nucleotides are annotated for adenine (Ade), cytosine (Cyt), guanine (Gua), and uracil (Ura). Not shown is $\mathrm{C}^{\prime}$ that has doublet splitting instead of triplet seen in the uniformly labeled NMP sample 
spectra is important for such studies and for efforts in monitoring RNA-drug interactions (e.g., Thomas and Hergenrother 2008).

While exceptional resolution is obtained with this new label, the fully enzymatic methods can yield $>95 \%$ label at the $\mathrm{Cl}^{\prime}$ position compared to the $3-5 \%$ obtained here. However, the fully enzymatic method is limited to piecemeal labeling of each ribose position using site specifically labeled glucose at increased cost. The enzymatic method also requires the coupling of the base moiety to the labeled sugar component. Unfortunately the selectively labeled bases required for coupling are not commercially available in useful forms and those available are quite pricey.

In addition to cost considerations, it is important to ascertain the usefulness of site specific labels under conditions of broadened resonances that accompany RNA of increased size. By dissolving the labeled nucleotides in 95\% w/w per deuterated glycerol, we can take advantage of the increased viscosity of the glycerol as a function of temperature. At $30^{\circ} \mathrm{C}$ the viscosity of glycerol is about 240 times that of water and at this temperature most of the base resonances are reduced in intensity in the nonconstant time ${ }^{13} \mathrm{C}$ HSQC spectrum such that the resonances for Cyt C5 and Pur C8 are barely visible in the spectrum (Fig. 5a). The reduction in intensity is consistent with increased overall correlation time and rapid signal decay. Use of the non-constant time ${ }^{13} \mathrm{C}$ TROSY experiment, as expected, rescues these signals (Fig. 5b). It is clear that these and other new experiments can be designed to probe RNA-ligand interactions at very high resolution.

Additionally a number of important spin relaxation applications benefit significantly from the selective ${ }^{13} \mathrm{C}$ labeling strategy. These include obtaining accurate relaxation parameters such as ${ }^{13} \mathrm{C}-\mathrm{CPMG}$ based relaxation dispersion rates for quantifying millisecond (ms) time-scale processes, as well as longitudinal relaxation rate $\left(R_{1}\right)$ and proton-carbon heteronuclear Overhauser effect (NOE; Yamazaki et al. 1994; Dayie and Wagner 1997) important for quantifying ns-ps time-scale motions in RNA (Johnson et al. 2006; Johnson and Hoogstraten 2008).

Finally, conventional proton detected experiments are deemed more valuable because of higher sensitivity compared to carbon-detected ones. However, advances in cryoprobe technology and higher fields have made carbondetected experiments entirely feasible and, in the case of extracting residual dipolar coupling, an excellent alternative to proton-detected methods that suffer from ${ }^{1} \mathrm{H}-{ }^{1} \mathrm{H}$ dipolar interactions (Fiala and Sklenár 2007). Thus selectively enriching the non-protonated carbon position is potentially valuable for obtaining additional structural information other than that associated with protonated sites. (a)

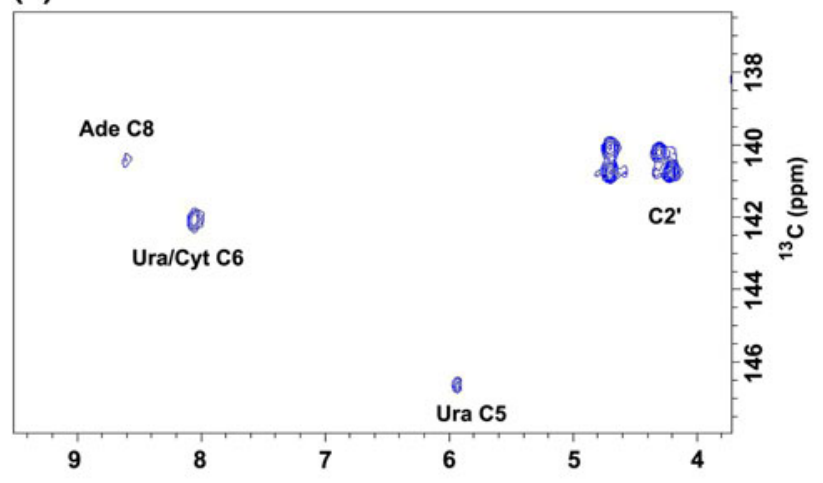

(b)

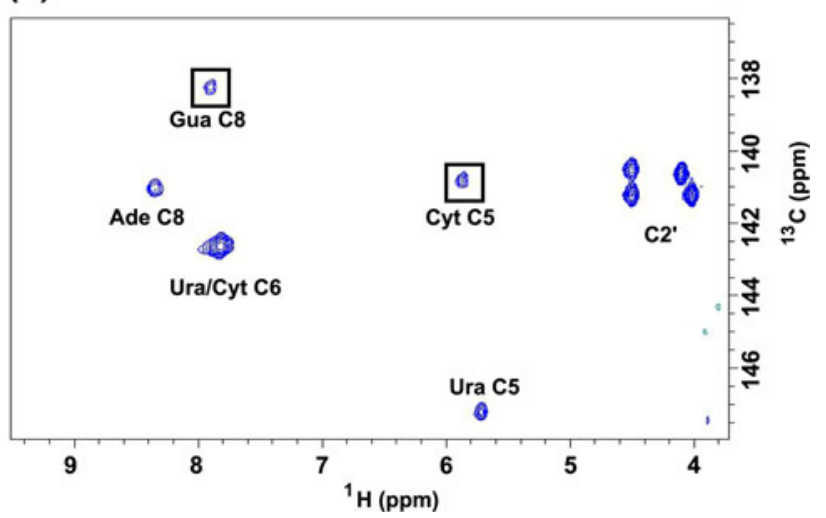

Fig. 5 Comparison of non-constant time sensitivity-enhanced a HSQC and b TROSY of selective ${ }^{13} \mathrm{C}$-enriched nucleotides dissolved in $95 \% \mathrm{w} / \mathrm{v}$ d8-glycerol at $30^{\circ} \mathrm{C}$ for all 4 rNMPs derived from $\mathrm{K} 10$ bacterial culture. Base correlations are depicted. The ribose $\mathrm{C}^{\prime}$ resonances that normally resonate between 73.7 and $74.7 \mathrm{ppm}$ and Cyt and Ura C5 resonances at $96.67 \mathrm{ppm}$ and $102.69 \mathrm{ppm}$ respectively (in a decoupled HSQC) are folded in. Identical acquisition and processing parameters were used. The time domain matrices were processed without apodization functions. As expected the TROSY peaks are right and down shifted from the decoupled HSQC peaks. Two resonances that are either very weak or absent in the HSQC spectrum are boxed

\section{Conclusion}

We have taken advantage of the versatility of growing an E. coli strain deficient in the glucose-6-phosphate dehydrogenase enzyme (K10) of the pentose phosphate pathway in chemically defined minimal media to synthesize nucleotides labeled with stable isotopes of ${ }^{13} \mathrm{C}$ and ${ }^{15} \mathrm{~N}$ for structural and molecular dynamics characterizations. By combining ${ }^{13} \mathrm{C}$-labeled glycerol with ${ }^{13} \mathrm{C}$-sodium formate, the enrichment of ${ }^{13} \mathrm{C}$ label is increased for all the protonated carbon sites that are of considerable interest for RNA NMR spectroscopy without introducing significant multiplet splitting at C5/C6 in the Pyr ring and $\mathrm{C}^{\prime} / \mathrm{C}^{\prime} /$ $\mathrm{C}^{\prime} / \mathrm{C}^{\prime}$ in the ribose ring. Introduction of ${ }^{15} \mathrm{~N}$ labeling provides another method for estimating the degree of ${ }^{13} \mathrm{C}$ label incorporation using a long range ${ }^{15} \mathrm{~N}$ HSQC with the 
carbon decoupling field turned off during acquisition. This efficient and inexpensive method for preparing ribonucleotides with these distributions of ${ }^{13} \mathrm{C}$ enrichment will likely minimize not just scalar couplings but also splittings from long-range dipolar couplings, thereby providing greater spectral quality than normally obtained with fully labeled nucleotides. Use of these nucleotides should therefore allow high resolution probing of RNA-ligand interactions, the measurement of structurally useful parameters such as chemical shift anisotropy-offsets, and the accurate extraction of relaxation parameters such as chemical exchange lifetimes from power dependence of $\mathrm{R}_{1 \rho}$ on the strength of the spinlock fields.

Acknowledgments This work was supported in part by the NanoBiotechnology Award and the National Institutes of Health grant GM077326 to T.K.D. The authors thank Profs. David Fushman and Vitali Tugarinov (University of Maryland) for useful discussions and Jacob Sama for assistance with the initial stages of the research.

Open Access This article is distributed under the terms of the Creative Commons Attribution Noncommercial License which permits any noncommercial use, distribution, and reproduction in any medium, provided the original author(s) and source are credited.

\section{References}

Batey RT, Inada M, Kujawinski E, Puglisi JD, Williamson JR (1992) Preparation of isotopically labeled ribonucleotides for multidimensional NMR spectroscopy of RNA. Nucleic Acids Res 20:4515-4523

Batey RT, Battiste JL, Williamson JR (1995) Preparation of isotopically enriched RNAs for heteronuclear NMR. Methods Enzymol 261:300-322

Bax A, Freeman R (1981) Investigation of complex networks of spin-spin coupling by two-dimensional NMR. J Magn Reson 44:542-561

Bax A, Mehlkopf AF, Smidt J (1979) Homonuclear broad-band decoupled absorption spectra. J Magn Reson 35:167-169

Bax A, Ikura M, Kay LE, Torchia DA, Tschudin R (1990) Comparison of different modes of two-dimensional reverse correlation NMR for the study of proteins. J Magn Reson 86: 304-318

Bodenhausen G, Ruben DJ (1980) Natural abundance nitrogen-15 NMR by enhanced heteronuclear spectroscopy. Chem Phys Lett 69:185-189

Brutscher B, Boisbouvier J, Kupce E, Tisne C, Dardel F, Marion D, Simorre JP (2001) Base-type-selective high-resolution ${ }^{13} \mathrm{C}$ edited NOESY for sequential assignment of large RNAs. J Biomol NMR 19:141-151

Czisch M, Boelens R (1998) Sensitivity enhancement in the TROSY experiment. J Magn Reson 134:158-160

D'Souza V, Dey A, Habib D, Summers MF (2004) NMR structure of the 101-nucleotide core encapsidation signal of the Moloney murine leukemia virus. J Mol Biol 337:427-442

Dayie KT (2005) Resolution enhanced homonuclear carbon decoupled triple resonance experiments for unambiguous RNA structural characterization. J Biomol NMR 32:129-139

Dayie KT (2008) Key labeling technologies to tackle sizeable problems in RNA structural biology. Int J Mol Sci 9:12141240
Dayie KT, Wagner G (1997) Carbonyl carbon probe of local mobility in ${ }^{13} \mathrm{C},{ }^{15} \mathrm{~N}$-enriched proteins using high resolution NMR. J Am Chem Soc 119:7797-7806

Edwards JS, Palsson BO (2000) The Escherichia coli MG1655 in silico metabolic genotype: its definition, characteristics, and capabilities. Proc Natl Acad Sci 97:5528-5533

Fiala R, Sklenár V (2007) ${ }^{13}$ C-detected NMR experiments for measuring chemical shifts and coupling constants in nucleic acid bases. J Biomol NMR 39:153-163

Fischer E, Sauer U (2003) Metabolic flux profiling of Escherichia coli mutants in central metabolism using GC-MS. Eur J Biochem 270:880-891

Fraenkel DG (1968) Selection of Escherichia coli mutants lacking glucose-6-phosphate dehydrogenase or gluconate-6-phosphate dehydrogenase. J Bacteriol 95:1267-1271

Gross A, Abril O, Lewis JM, Geresh S, Whitesides GM (1983) Practical synthesis of 5-phospho-D-ribosyl. alpha.-1-pyrophosphate (PRPP): enzymatic routes from ribose 5-phosphate or ribose. J Am Chem Soc 105:7428-7435

Grzesiek S, Bax A (1992) Improved 3D triple resonance NMR techniques applied to a $31 \mathrm{kDa}$ protein. J Magn Reson 96: $432-440$

Gumbs OH, Padgett RA, Dayie KT (2006) Fluorescence and solution NMR study of the active site of a $160-\mathrm{kDa}$ group II intron ribozyme. RNA 12:1693-1707

Hines JV, Landry SM, Varani G, Tinoco I (1994) Carbon-proton scalar couplings in RNA-3D heteronuclear and 2D isotopeedited NMR of A C-13 labeled extra-stable hairpin. J Am Chem Soc 116:5823-5831

Hoffman DW, Holland JA (1995) Preparation of C-13-labeled ribonucleotides using acetate as an isotope source. Nucleic Acids Res 23:3361-3362

Hoogstraten CG, Johnson JE (2008) Metabolic labeling: taking advantage of bacterial pathways to prepare spectroscopically useful isotope patterns in proteins and nucleic acids. Concepts Magn Reson Part A 32:34-55

Johnson JE Jr, Hoogstraten CG (2008) Extensive backbone dynamics in the GCAA RNA tetraloop analyzed using ${ }^{13} \mathrm{C}$ NMR spin relaxation and specific isotope labeling. $\mathrm{J}$ Am Chem Soc 130:16757-16769

Johnson JE, Julien KR, Hoogstraten CG (2006) Alternate-site isotopic labeling of ribonucleotides for NMR studies of ribose conformational dynamics in RNA. J Biomol NMR 35: 261-274

Kay LE, Keifer P, Saarinen T (1992) Pure absorption gradient enhanced heteronuclear single quantum correlation spectroscopy with improved sensitivity. J Am Chem Soc 114:10663-10665

Kirkpatrick C, Maurer LM, Oyelakin NE, Yoncheva YN, Maurer R, Slonczewski JL (2001) Acetate and formate stress: opposite responses in the proteome of Escherichia coli. J Bacteriol 183:6466-6477

Knappe J, Blaschkowski HP, Gröbner P, Schmitt T (1974) Pyruvate formate-lyase of Escherichia coli: the acetyl-enzyme intermediate. Eur J Biochem 50:253-263

Kupce E, Wagner G (1996) Multisite band-selective decoupling in proteins. J Magn Reson B 110:309-312

Latham MR, Brown DJ, McCallum SA, Pardi A (2005) NMR methods for studying the structure and dynamics of RNA. Chembiochem 6:1492-1505

Louis JM, Martin RG, Clore GM, Gronenborn AM (1998) Preparation of uniformly isotope-labeled DNA oligonucleotides for NMR spectroscopy. J Biol Chem 273:2374-2378

Lu K, Miyazaki Y, Summers MF (2010) Isotope labeling strategies for NMR studies of RNA. J Biomol NMR 46:113-125

Lundström P, Teilum K, Carstensen T, Bezsonova I, Wiesner S, Hansen DF, Religa TL, Akke M, Kay LE (2007) Fractional 13C 
enrichment of isolated carbons using [1-13C]- or [2-13C]glucose facilitates the accurate measurement of dynamics at backbone Calpha and side-chain methyl positions in proteins. J Biomol NMR 38:199-212

Masse JE, Bortmann P, Dieckmann T, Feigon J (1998) Simple, efficient protocol for enzymatic synthesis of uniformly ${ }^{13} \mathrm{C}$, ${ }^{15} \mathrm{~N}$-labeled DNA for heteronuclear NMR studies. Nucleic Acids Res 26:2618-2624

Meissner A, Schulte-Herbrueggen T, Briand J, Sorensen OW (1998) Double spin-state-selective coherence transfer. Application for two-dimensional selection of multiplet components with long transverse relaxation times. Mol Phys 96:1137-1142

Michnicka MJ, Harper JW, King GC (1993) Selective isotopic enrichment of synthetic RNA: application to the HIV-1 TAR element. Biochemistry 32:395-400

Milecki J (2002) Specific labelling of nucleosides and nucleotides with ${ }^{13} \mathrm{C}$ and ${ }^{15} \mathrm{~N}$. J Label Comp Radiopharm 45:307-337

Mueller L (1979) Sensitivity enhanced detection of weak nuclei using heteronuclear multiple quantum coherence. J Am Chem Soc 101:4481-4484

Nelissen FH, Girard FC, Tessari M, Heus HA, Wijmenga SS (2009) Preparation of selective and segmentally labeled single-stranded DNA for NMR by self-primed PCR and asymmetrical endonuclease double digestion. Nucleic Acids Res 37:e114

Nelson DL, Cox MM (2008) Lehninger principles of biochemistry. W.H. Freeman, New York

Nicolas C, Kiefer P, Letisse F, Krömer J, Massou S, Soucaille P, Wittmann C, Lindley ND, Portais JC (2007) Response of the central metabolism of Escherichia coli to modified expression of the gene encoding the glucose-6-phosphate dehydrogenase. FEBS Lett 581:3771-3776

Nikonowicz EP (2001) Preparation and use of ${ }^{2} \mathrm{H}$-labeled RNA oligonucleotides in nuclear magnetic resonance studies. Methods Enzymol 338:320-341

Nikonowicz EP, Sirr A, Legault P, Jucker FM, Baer LM, Pardi A (1992) Preparation of ${ }^{13} \mathrm{C}$ and ${ }^{15} \mathrm{~N}$ labelled RNAs for heteronuclear multi-dimensional NMR studies. Nucleic Acids Res 20:4507-4513

Paliy O, Gunasekera TS (2007) Growth of E-coli BL21 in minimal media with different gluconeogenic carbon sources and salt contents. Appl Microbiol Biotechnol 73:1169-1172

Palmer AG, Cavanagh J, Wright PE, Rance M (1991) Sensitivity improvement in proton-detected two-dimensional heteronuclear correlation NMR spectroscopy. J Magn Reson 93:151-170

Parkin DW, Leung HB, Schramm VL (1984) Synthesis of nucleotides with specific radiolabels in ribose. Primary $14 \mathrm{C}$ and secondary $3 \mathrm{H}$ kinetic isotope effects on acid-catalyzed glycosidic bond hydrolysis of AMP, dAMP, and inosine. J Biol Chem 259:94119417

Pervushin K, Wider G, Wuthrich K (1998) Single transition-to-single transition polarization transfer (ST2-PT) in [15 N, 1H]-TROSY. J Biomol NMR 12:345-348

Ponchon L, Dardel F (2007) Recombinant RNA technology: the tRNA scaffold. Nat Methods 4:571-576

Ponchon L, Beauvais G, Nonin-Lecomte S, Dardel F (2009) A generic protocol for the expression and purification of recombinant RNA in Escherichia coli using a tRNA scaffold. Nat Prot 4:947-959
Rance M, Loria JP, Palmer AG III (1999) Sensitivity improvement of transverse relaxation-optimized spectroscopy. J Magn Reson 136:92-101

Sambrook J, Russell DW (2001) Molecular cloning: a laboratory manual. Cold Spring Harbor Laboratory, Cold Spring Harbor, NY

Schulte-Herbrüggen T, Sorensen OW (2000) Clean TROSY: compensation for relaxation-induced artifacts. J Magn Reson 144: $123-128$

Schultheisz HL, Szymczyna BR, Scott LG, Williamson JR (2008) Pathway engineered enzymatic de novo purine nucleotide synthesis. ACS Chem Biol 3:499-511

Scott LG, Tolbert TJ, Williamson JR (2000) Preparation of specifically ${ }^{2} \mathrm{H}$ - and ${ }^{13} \mathrm{C}$-labeled ribonucleotides. Methods Enzymol 317:18-38

Shaka AJ, Barker PB, Freeman R (1985) Computer-optimized decoupling scheme for wideband applications and low-level operation. J Magn Reson 64:547-552

Studier FW (2005) Protein production by auto-induction in highdensity shaking cultures. Protein Expr Purif 41:207-234

Thauer RK, Kirchniawy FH, Jungermann KA (1972) Properties and function of the pyruvate-formate-lyase reaction in clostridiae. Eur J Biochem 27:282-290

Thomas JR, Hergenrother PJ (2008) Targeting RNA with small molecules. Chem Rev 108:1171-1224

Tolbert TJ, Williamson JR (1996) Preparation of specifically deuterated RNA for NMR studies using a combination of chemical and enzymatic synthesis. J Am Chem Soc 118:7929-7940

Tolbert TJ, Williamson JR (1997) Preparation of specifically deuterated and ${ }^{13} \mathrm{C}$-Labeled RNA for NMR studies using enzymatic synthesis. J Am Chem Soc 119:12100-12108

van de Ven FJM, Philippens MEP (1992) Optimization of constanttime evolution in multidimensional experiments. J Magn Reson 97:637-644

Voet D, Voet JG, Pratt CW (2008) Fundamentals of biochemistry, 3rd edn. Wiley, New York

Weigelt J (1998) Single scan, sensitivity- and gradient-enhanced TROSY for multidimensional NMR experiments. J Am Chem Soc 120:10778-10779

Werner MH, Gupta V, Lambert LJ, Nagata T (2001) Uniform ${ }^{13} \mathrm{C} /{ }^{15} \mathrm{~N}$-labeling of DNA by tandem repeat amplification. Methods Enzymol 338:283-304

Wijmenga SS, van Buuren BNM (1998) The use of NMR methods for conformational studies of nucleic acids. Prog NMR Spectroscopy 32:287-387

Yamazaki T, Muhandiram R, Kay LE (1994) NMR experiments for the measurement of carbon relaxation properties in highly enriched, uniformly $13 \mathrm{C}, 15 \mathrm{~N}$-labeled proteins: application to $13 \mathrm{C} \alpha$ carbons. J Am Chem Soc 114:8266-8278

Zhao J, Baba T, Mori H, Shimizu K (2004) Effect of zwf gene knockout on the metabolism of Escherichia coli grown on glucose or acetate. Metab Eng 6:164-174

Zhu G, Xia Y, Kong XM, Sze KH (1999) 2D and 3D TROSYenhanced NOESY of ${ }^{15} \mathrm{~N}$ labeled proteins. J Biomol NMR 13:77-81

Zimmer DP, Crothers DM (1995) NMR of enzymatically synthesized uniformly 13C, 15 N-labeled DNA oligonucleotides. Proc Natl Acad Sci 92:3091-3095 